\title{
Electrochemical sensing using magnetic molecularly imprinted polymer particles previously captured by a magneto-sensor
}

\author{
Gerson A. Ruiz-Córdova ${ }^{\mathrm{a}, \mathrm{b}, \mathrm{c}}$, Sabir Khan ${ }^{\mathrm{b}, \mathrm{c}}$, Luís Moreira Gonçalves ${ }^{\mathrm{d}, \mathrm{e}}$, Maria Isabel Pividorif \\ Gino Picasso $^{\mathrm{a}}$, Maria Del Pilar T. Sotomayor ${ }^{\mathrm{b}, \mathrm{c}, *}$ \\ ${ }^{a}$ Laboratory of Physical Chemistry Research, Faculty of Sciences, National University of Engineering, Lima, Peru \\ b Department of Analytical Chemistry, Institute of Chemistry, UNESP - Univ Estadual Paulista, Araraquara, SP, Brazil \\ ${ }^{\mathrm{c}}$ National Institute for Alternative Technologies of Detection, Toxicological Evaluation and Removal of Micropollutants and Radioactives (INCT-DATREM), Araraquara, \\ $S P$, Brazil \\ d REQUIMTE/LAQV, Faculdade de Ciências, Universidade do Porto, Porto, Portugal \\ e Departamento de Química Fundamental, Instituto de Química, Universidade de São Paulo (USP), São Paulo, SP, Brazil \\ ${ }^{\mathrm{f}}$ Universitat Autònoma de Barcelona, Barcelona, Spain
}

\section{A R T I C L E I N F O}

\section{Keywords:}

2,4-Dinitrochlorobenzene (CDNB)

Electroanalysis

Magnetic beads

Modified working electrode

Nanoparticles

Stripping voltammetry

\begin{abstract}
A B S T R A C T
The determination of 1-chloro-2,4-dinitrobenzene (CDNB) was used as a proof-of-concept to a simple analytical practical configuration applying magnetic molecularly imprinted particles (mag-MIPs). Mag-MIPs were captured from an emulsion by a home-made magneto-sensor (where a small magnet was entrapped by a graphite-epoxy composite) and then, this sensor, was transferred to the solution containing the analyte, where, after binding to the mag-MIPs, the analyte was directly analysed using differential pulse voltammetry (DPV) since the magnetosensor acted as the working electrode. After optimization, a detection limit of $6.0 \mu \mathrm{mol} \mathrm{L}{ }^{-1}$ with a RSD of $2.7 \%$ was achieved along with suitable recoveries and selectivity. This methodology offers a different approach for electroanalytical methodologies using mag-MIPs.
\end{abstract}

\section{Introduction}

Since the early reports on magnetic separation technology, magnetic particles have been used as powerful and versatile options in many biotechnological applications [1], including with analytical intents, being the electrochemical biosensing an example of it [2]. The magnetic properties allow in a very simple and selective way, a quick separation due to straightforward manipulation [3].

Magnetic molecular imprinting polymers (mag-MIPs) are particles where MIPs (a biomimetic material containing gaps where the aimed analyte can selectively bind) surround a metallic core that is easily susceptible to an external magnetic field [4,5]. MIPs were idealized as a synthetic alternative to biological receptors, imitating antibodies, in some ways they can be considered as biomimetic polymers. MIPS have sites of molecular recognition for a specific molecule. Mag-MIPs combine the advantages of the magnetic beads with that of molecular imprinted polymers (such as the low cost of synthesis, less time consumed when compared with the traditional solid-phase extraction (SPE), high mechanical and chemical stability, and, most notably, a tailor-made selective recognition) [5-17].

In general, MIPs and mag-MIPs are used in chromatographic applications as an alternative to conventional adsorbents [17]. Herein, it is intended to have an electrochemical application making use of a magneto-sensor. Magneto-sensors can capture different functionalized magnetic beads making it possible to creatively develop different analytical approaches $[5,8,18-20]$. Despite their prominent advantages, such as good sensitivity [21] and 'user-friendliness', electrochemical techniques often suffer from poor selectivity towards the analyte species, an issue that can be solved recurring to a suitable sample pretreatment step (sample preparation) [22-29]. 1-chloro-2,4-dinitrobenzene (CDNB) is a toxic xenobiotic compound known to cause oxidative stress and cell death and a well-known allergenic [30-32], herein it was used as the proof-of-concept analyte.

\section{Experimental}

\subsection{Reagents}

All reagents used were of analytical grade.

Sodium dodecyl sulphate (SDS), CDNB, $\mathrm{Fe}_{2}\left(\mathrm{SO}_{4}\right)_{3} \cdot 9 \mathrm{H}_{2} \mathrm{O}$, $\mathrm{FeSO}_{4} \cdot 7 \mathrm{H}_{2} \mathrm{O}, \mathrm{K}_{4}\left[\mathrm{Fe}(\mathrm{CN})_{6}\right]$, oleic acid (OA), methacrylic acid (MA), ethylene glycol dimethacrylate (EGDMA), methylene diphenyl

\footnotetext{
* Corresponding author at: Department of Analytical Chemistry, Institute of Chemistry, UNESP - Univ Estadual Paulista, Araraquara, SP, Brazil

E-mail address: mpilar@iq.unesp.br (M.D.P.T. Sotomayor).
} 
diisocyanate-4 (MDI), bisphenol A (BPA), phloroglucinol were acquired from Sigma-Aldrich. Glycine, Tween 20, sodium chloride, potassium chloride, boric acid, acetic acid, potassium persulfate, n-hexane, chloroform and phosphoric acid were all purchased from Merck. Methanol and tetrahydrofuran were purchased from ACS Synth.

Ultrapure water (resistivity not lower than $18.2 \mathrm{M} \Omega \mathrm{cm}$ at $298 \mathrm{~K}$ ) from a Purelab Classic water purification system was used in all the experiments.

\subsection{Mag-MIPs synthesis}

Magnetic nanoparticles were prepared by the co-precipitation method, using $\mathrm{FeSO}_{4} \cdot 7 \mathrm{H}_{2} \mathrm{O}$ and $\mathrm{Fe}_{2}\left(\mathrm{SO}_{4}\right)_{3} \cdot 9 \mathrm{H}_{2} \mathrm{O}$ as the starting materials, and mixed with oleic acid (OA). This material was then encapsulated in a hydrophobic polymeric matrix, poly-(MA-co-EDGMA), by the mini-emulsion method. The mag-MIP selective to CDNB was synthesized over the magnetic-hydrophobic surface using the precipitation polymerization in the presence of the analyte, MDI, BPA and phloroglucinol, forming a core@shell structure. A magnetic non-imprinted polymer (mag-NIP) was prepared as a control polymer using the same procedure employed for the mag-MIP, but without the analyte.

Full details concerning the synthesis of the mag-MIPs, along with the full physicochemical characterization of these materials can be found in a recent publication [32].

\subsection{Apparatus and working electrode manufacturing}

Electrochemical measurements were performed using a PalmSens ${ }^{\circledast}$ 3 potentiostat. Final electrochemical measurements were performed in a Britton-Robison buffer solution $\left(\mathrm{H}_{3} \mathrm{BO}_{3} 0.04 \mathrm{~mol} \mathrm{~L}^{-1}, \mathrm{CH}_{3} \mathrm{COOH}\right.$ $0.04 \mathrm{~mol} \mathrm{~L}^{-1}$ and $\mathrm{H}_{3} \mathrm{PO}_{4} 0.04 \mathrm{~mol} \mathrm{~L}^{-1}$ ). Dissolved oxygen was removed by purging with nitrogen. A platinum wire was used as the counterelectrode (CE), and the pair $\mathrm{Ag} \mid \mathrm{AgCl}$ (in $\mathrm{KCl}, 3 \mathrm{~mol} \mathrm{~L}^{-1}$ ) was used as the reference electrode (RE). The working electrode (WE) was homebuilt, a diagram of its manufacturing is shown in Fig. 1A. Graphite powder and epoxy resin were hand-mixed in a 1:4 $(\mathrm{w} / \mathrm{w})$ ratio. This mixture was thoroughly hand-mixed to ensure the uniform dispersion of the graphite powder throughout the polymer. The resulting paste was placed to a depth of $3 \mathrm{~mm}$ in a cylindrical PVC sleeve body (6 $\mathrm{mm}$ i.d.) with a copper plate as electrical contact [24]. A small neodymium magnet ( $3 \mathrm{~mm}$ i.d.) was placed into the centre of this electrode after the addition of a thin layer of composite paste in order to avoid direct contact between the magnet and the electrical connector. After filling the electrode body gap completely with the soft paste, the electrode was tightly packed. An image of the final electrode is shown in Fig. 1B. Before each use, the electrode surface was renewed by a simple polishing procedure [25].

\section{Results and discussion}

The aim of this work was to experiment a different analytical methodology for mag-MIPs taking advantage of a magneto-sensor. This is schematically explained in Fig. 2. Initially, the prepared mag-MIPs were dispersed in a glycine solution, by sonication for two hours in order to obtain a reproducible homogenous suspension. Afterwards, the mag-MIPs were seized, in a $20 \mathrm{~s}$ period, becoming 'concentrated' in the surface of the home-made magneto-sensor [24]. Then, this magnetosensor with a modified working surface was transferred to the electrochemical cell sample, where the analyte was captured in the analytesized mag-MIPs' holes and was electrochemically quantified (CDNB is electrochemically active), thus becoming the magneto-sensor a working electrode. Since the mag-MIPs were concentrated in the electrode surface and not within a carbon paste, a higher and quicker analyte binding was achieved.

As is shown in the literature, at $\mathrm{pH}$ of 2.0 , the reduction peak of CDNB is around $-0.4 \mathrm{~V}$ ( $\alpha$ in Fig. 3A) [33]. Moreover, in literature it is suggested that it is a reductive cleavage of the carbon-chlorine bond $[34,35]$; a further mechanistic discussion can be found in literature [35]. Optimized parameters ended up being the following: potential of deposition (for $60 \mathrm{~s}$ ) of $-0.20 \mathrm{~V}$, electrochemical window from -0.20 to $-0.50 \mathrm{~V}$, potential step of $4 \mathrm{mV}$, potential pulse of $0.12 \mathrm{~V}$ with a scan rate of $4 \mathrm{mV} \mathrm{s}^{-1}$ (i.e. $200 \mathrm{~ms}$ per pulse). The analytical methodology was also optimized concerning different times in the several steps, namely the time of dispersion $\left(t_{\text {dis }}\right)$, i.e. the time the Mag-MIPs were shaken within the Tween solution creating the emulsion, time of collection $\left(t_{\mathrm{col}}\right)$, i.e. the time the magneto-sensor spent capturing the mag-MIPs into its surface and equilibration time $\left(t_{\mathrm{eq}}\right)$, i.e. the time the magneto-sensor was placed in the sample previous to the electrochemical stripping. Longer dispersion times originated larger currents up to certain point since an emulsion with suitable dispersion was already formed. In the same conditions ([CDNB] of $1 \times 10^{-3} \mathrm{~mol} \mathrm{~L}^{-1}$, room temperature, scan rate of $20 \mathrm{mV} \mathrm{s}^{-1}$ ): for $30 \mathrm{~min}-35 \mu \mathrm{A}$, $60 \mathrm{~min}-67 \mu \mathrm{A}$ and $120 \mathrm{~min}-90 \mu \mathrm{A}$. Hence a time of $120 \mathrm{~min}$ was chosen. The optimization of $t_{\mathrm{col}}$ and $t_{\mathrm{eq}}$ is shown in Fig. 3B. Larger currents were obtained for shorter $t_{\mathrm{col}}$ and longer $t_{\mathrm{eq}}$, it seems that longer capturing times are creating more than one mag-MIP layer and, therefore, not just making the analyte further apart from the electrode surface but also complicating the electron transfer. For a better understanding of the whole process, a mention to these times also appears in the schematics of Fig. 2. The temperature of analyte binding to the mag-MIPs was also optimized, and, as it is shown in Fig. 3A, a higher temperature, for the same period of time, clearly increases the signal. This is not surprising since, in general an increase in temperature may enhance reaction rates as well as favouring adsorptive processes [36].

The corresponding calibration curve $(n=7)$ had the following analytical parameters (Fig. 4): a $r^{2}$ of 0.983 , peak current $(\mu \mathrm{A})=$ $(1.76 \pm 0.10) \times[\mathrm{CDNB}]\left(\mu \mathrm{mol} \mathrm{L}{ }^{-1}\right)-(4.5 \pm 3.1)$, limit of detection (LOD) and quantification (LOQ) of 6.0 and $20.0 \mu \mathrm{mol} \mathrm{L}^{-1}$ (1.2 and $4.1 \mathrm{mg} \mathrm{L}^{-1}$ ), respectively. LOD and LOQ were calculated as three and ten times the standard deviation of the intercept/slope, respectively, these are comparable to other works in literature using HPLC-UV [31]. Repeatability was evaluated comparing five calibration curves, the relative standard deviation (RSD) obtained was of $2.7 \%$.

When comparing the mag-MIPs with the corresponding mag-NIPs
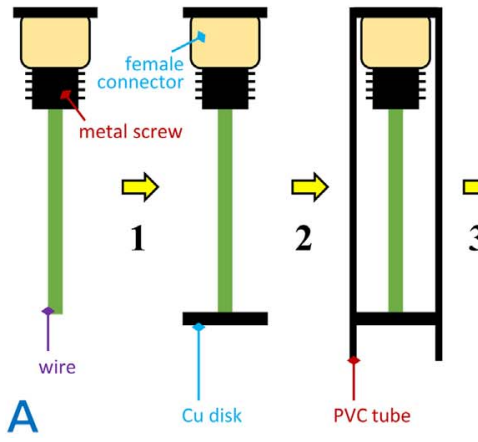

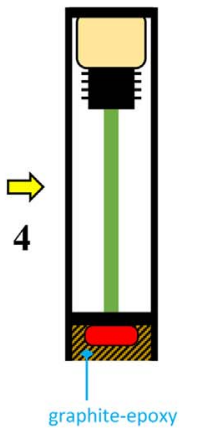

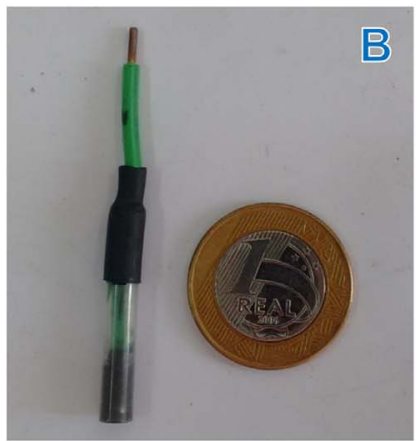

Fig. 1. A - Schematics of the manufacturing of the magneto-sensor, a copper disc connector is placed on the tip of the conducting wire (1), then everything is inserted in a PVC tube (2), then the neodymium magnet is placed (3) and, finally, a thin layer of a graphite-epoxy composite is placed (4). B Photograph of the built magneto-sensor next to a 1 Brazilian real coin $(27 \mathrm{~mm}$ diameter) for scaling purposes. 

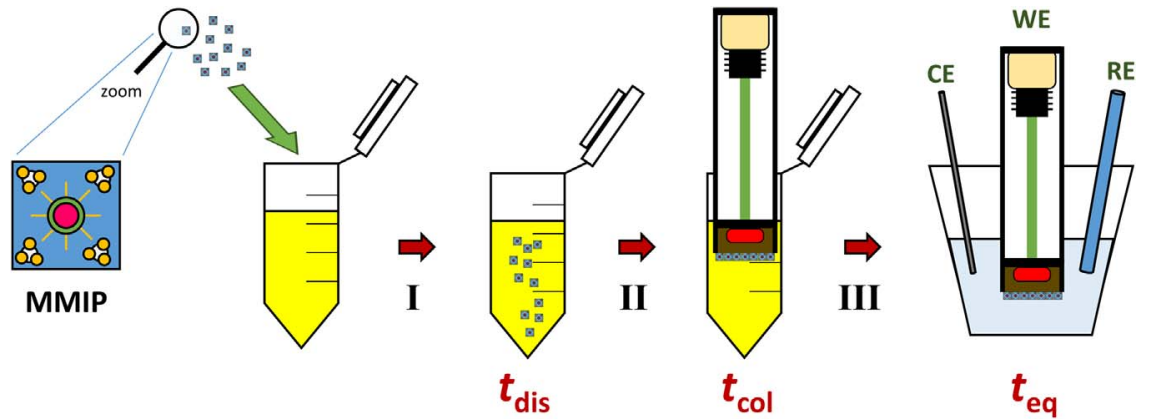

Fig. 2. Schematics of the analytical procedure, after placing the Mag-MIPs (I) Dispersion of the mag-MIPs (dispersion in a $3 \mathrm{mg} \mathrm{mL}^{-1}$ glycine buffer solution, at a $\mathrm{pH}$ of $2.0,0.1 \mathrm{~mol} \mathrm{~L}^{-1}$, Tween 20, $0.05 \%$ and $\mathrm{NaCl} 0.15 \mathrm{~mol} \mathrm{~L}^{-1}$ ); (II) Magnetic capture by the magneto-sensor; (III) Analyte binding to the mag-MIPs (in a $20 \mathrm{~mL}$ solution: $9 \mathrm{~mL}$ of the sample, $9 \mathrm{~mL}$ of phosphate buffer solution, $2 \mathrm{~mL}$ of ethanol).
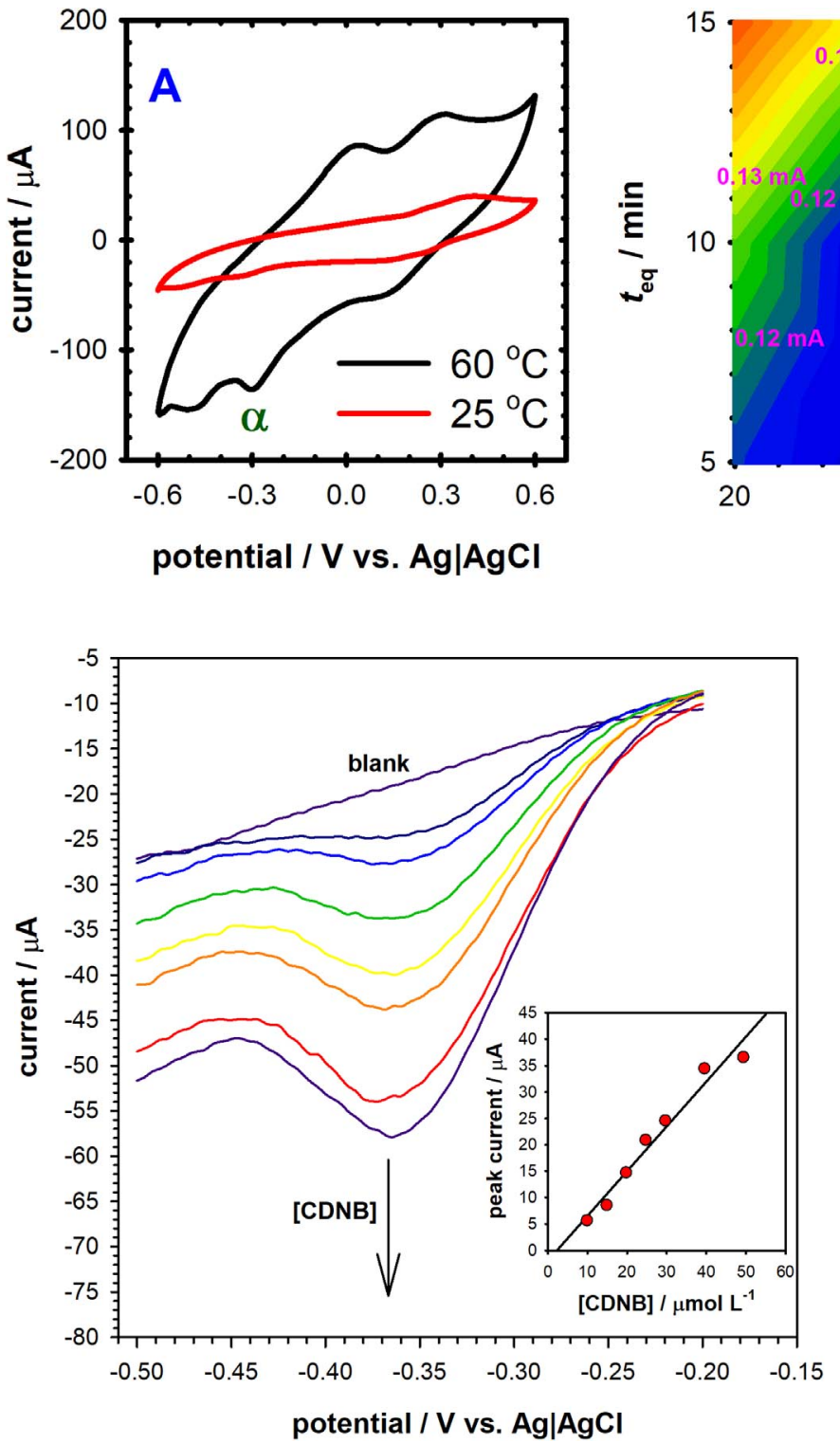

Fig. 4. Differential pulse voltammograms obtained in the optimized conditions, inlay the corresponding calibration curve: peak current vs. CDNB concentration.

(Fig. 5), not only larger signals were obtained with the mag-MIPs but also the mag-MIPs became saturated with much lower concentrations. In Fig. 5 it is also possible to observe that the linear range of mag-MIPs goes up to $200 \mathrm{mg} \mathrm{L}^{-1}$ (ca. $1 \mathrm{mmol} \mathrm{L}^{-1}$ ).

The sensor selectivity was evaluated by comparing the obtained signal with the analyte against other chemically analogous compounds. As it is shown in Fig. 6, molecules with a similar size to CDNB with a

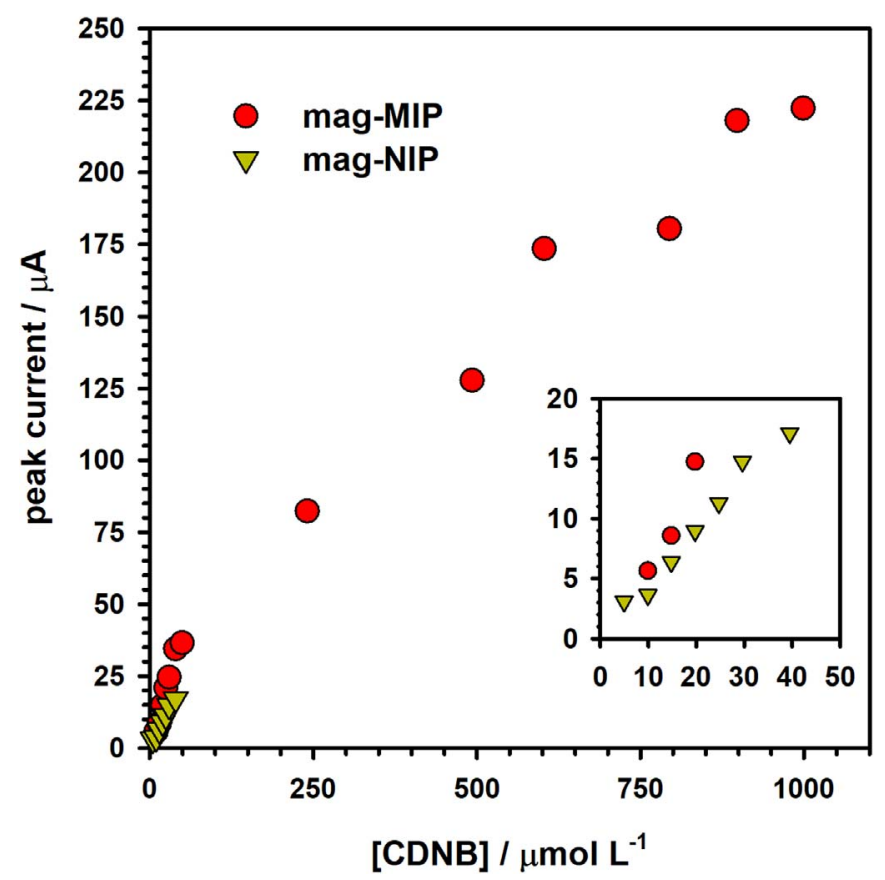

Fig. 5. Peak current using mag-MIPs and mag-NIPs.

nitrobenzene or a aminobenzene group gave origin to significant signals (ca. 50\% of CDNB), for all other tested compounds (even molecules with nitro groups but with a larger size) the results obtained were around $10 \%$ or less. Considering the selectivity of typical MIPs, the results were rather suitable for analytical purposes [13,37,38].

The methodology was applied in several spiked samples as displayed in Table 1. It is possible to conclude, from the slopes obtained, 


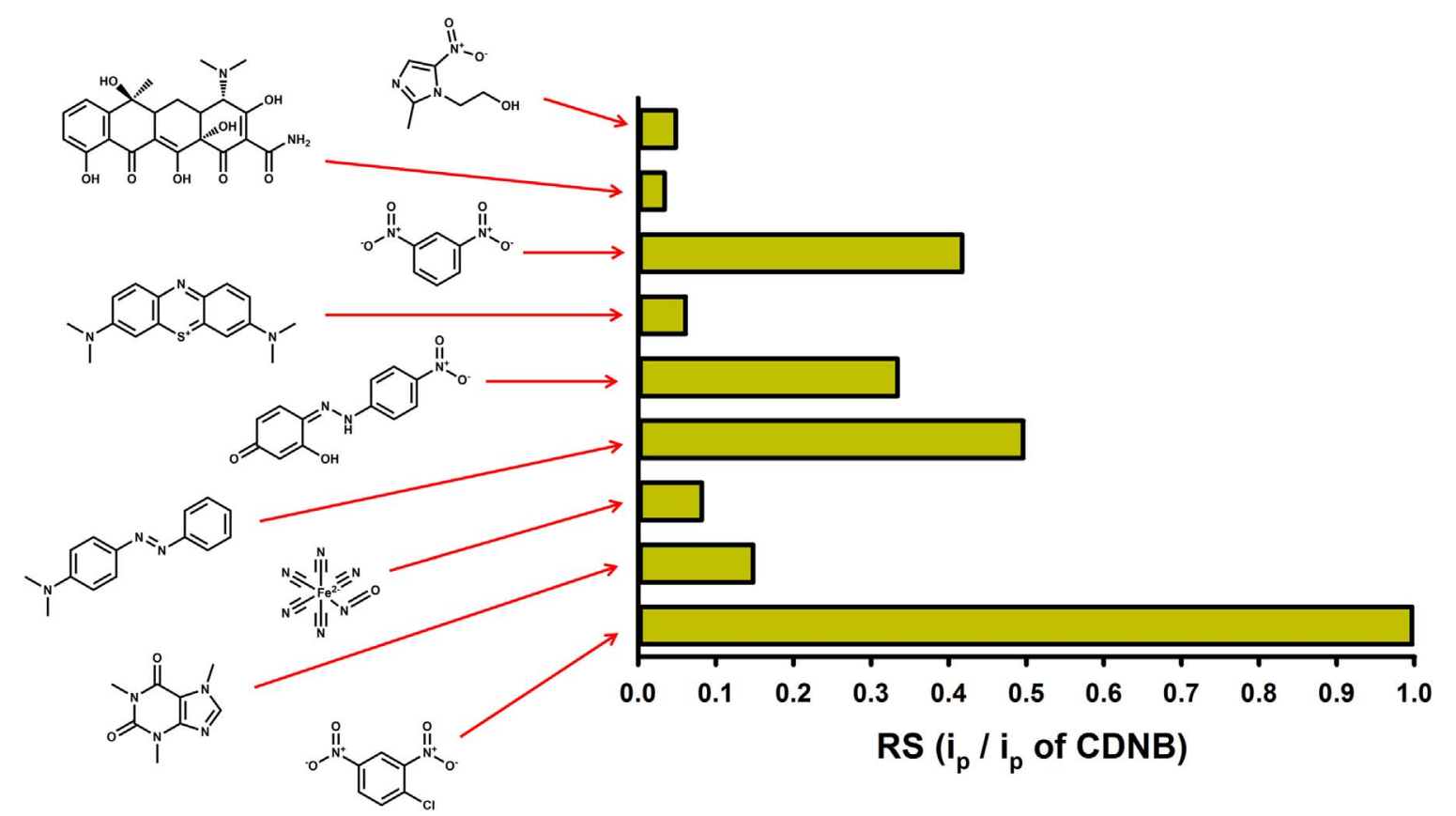

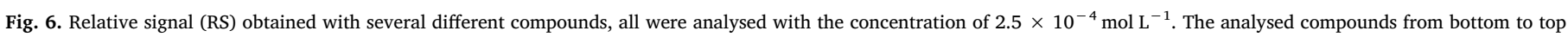

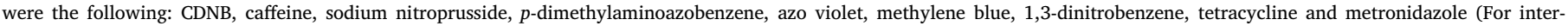
pretation of the references to color in this figure legend, the reader is referred to the web version of this article.).

Table 1

Analysis of 5 different water samples by the standard additions method.

\begin{tabular}{llll}
\hline water sample & {$[\mathrm{CDNB}]$} & slope $/ \boldsymbol{\mu A ~ L ~} \mathbf{m m o l}^{-\mathbf{1}}$ & $\mathbf{r}^{\mathbf{2}}$ \\
\hline River Chibarro & $<\mathrm{LOQ}$ & $4.1 \pm 0.3$ & 0.995 \\
Bottled water & $<\mathrm{LOQ}$ & $7.9 \pm 0.9$ & 0.987 \\
River Tiete & $<\mathrm{LOQ}$ & $4.0 \pm 0.6$ & 0.975 \\
River Jabarro & $<\mathrm{LOQ}$ & $4.5 \pm 0.2$ & 0.998 \\
Tap water & $<\mathrm{LOQ}$ & $8.0 \pm 0.1$ & 0.999 \\
\hline
\end{tabular}

that there is a matrix effect, thus quantification should be performed by the standard additions method. Recovery studies were performed with CNDB concentrations of 24.7, 49.4 and $74.1 \mu \mathrm{mol} \mathrm{L}^{-1}$ and the obtained results were $105 \%, 105 \%$ and $103 \%$, respectively.

Although there are many works using mag-MIPs or MIPs and electrochemical detection [8,39-41], the particular analytical configuration in this work is novel. In recent literature, one can indeed find many different electrode configurations, from innovative materials like graphene $[10,42]$ to not so recent materials like multiwall carbon nanotubes $[8,43]$. These are more complex and more expensive systems, albeit in some cases with other advantages. There has also been innovation in terms of the electrochemical technique used, per example, impedimetric measurements gave origin to sensible results, yet with longer times of analysis and added complications to data interpretation [44]. Nevertheless, the main difference from this work to the others is its analytical configuration, i.e. usually the mag-MIPs are left to bind with the analyte in the sample and then removed using the magnetosensor, then the electrochemical measurement is performed in a buffer solution $[8,37,40,41]$. Herein, the Mag-MIPs particles are dispersed homogenously and then the particles are pre-concentrated in the electrode surface within the solution and the analytical measurement followed. This approach shows advantages in terms of simplicity, sensitivity, low-cost and versatility. Since the final measurement occurs in the sample, this allows, for example, to previously modify the electrodes and then use them whenever they are required (the absence of biological element allows them to have longer shelf life), thus increasing their portability.

\section{Conclusions}

This work shows a different approach to the use of mag-MIPs, whose application is enhanced by utilizing a magneto-sensor/working electrode. The magneto-sensor concentrates the mag-MIPs in its surface, subsequently, it is transferred into the sample and, in situ, directly voltammetrically analyses 1-chloro-2,4-dinitrobenzene (CDNB). The developed sensor showed suitable analytical parameters and the methodology, with the adequate mag-MIPs, has the potential to be used with many other analytes.

\section{Acknowledgements}

The authors would like to express their sincerest gratitude and indebtedness to the Research Funding Agencies Programa Nacional de Innovación para Competitividad y Productividad - InnovatePeru (Convenio 513-INNOVATEPERU-ECIP-2015), CNPq (303690/2012-7 and 465571/2014-0), FAPESP (2014/25264-3, 2014/50945-4 and 2016/06926-0) for the financial support. GP wishes to acknowledge IGI-Institute of Research of National University of Engineering of Lima Peru (project FC-F-24-2017). The Spanish Ministry of Economy and Competitiveness (MINECO), Madrid (project BIO2016-75751-R) is also acknowledged. SK wishes to acknowledge PRODOC-CAPES. LMG (SFRH/BPD/76544/2011 and FCT/13277/4/8/2015S) wishes to acknowledge Fundação para a Ciência e a Tecnologia (FCT).

\section{Conflicts of interest}

Authors declare no conflicts of interest.

\section{References}

[1] A. Rembaum, R.C.K. Yen, D.H. Kempner, J. Ugelstad, Cell labeling and magnetic separation by means of immunoreagents based on polyacrolein microspheres, J. Immunol. Methods 52 (1982) 341-351, http://dx.doi.org/10.1016/0022-1759(82) 90006-0.

[2] P. Yáñez-Sedeño, S. Campuzano, J.M. Pingarrón, Magnetic particles coupled to disposable screen printed transducers for electrochemical biosensing, Sensors 16 (2016) 1585, http://dx.doi.org/10.3390/s16101585. 
[3] J. He, M. Huang, D. Wang, Z. Zhang, G. Li, Magnetic separation techniques in sample preparation for biological analysis: a review, J. Pharm. Biomed. Anal. 101 (2014) 84-101, http://dx.doi.org/10.1016/j.jpba.2014.04.017.

[4] S. Hussain, S. Khan, S. Gul, M.I. Pividori, M.D.P.T. Sotomayor, A novel core@shell magnetic molecular imprinted nanoparticles for selective determination of folic acid in different food samples, React. Funct. Polym. 106 (2016) 51-56, http://dx. doi.org/10.1016/j.reactfunctpolym.2016.07.011.

[5] S. Ansari, M. Karimi, Recent configurations and progressive uses of magnetic molecularly imprinted polymers for drug analysis, Talanta 167 (2017) 470-485, http://dx.doi.org/10.1016/j.talanta.2017.02.049.

[6] L. Chen, S. Xu, J. Li, Recent advances in molecular imprinting technology: current status $\{$,$\} challenges and highlighted applications, Chem. Soc. Rev. 40$ (2011) 2922-2942, http://dx.doi.org/10.1039/C0CS00084A.

[7] S. Liebana, D. Brandao, S. Alegret, M.I. Pividori, Electrochemical immunosensors\{, genosensors and phagosensors for Salmonella detection, Anal. Methods 6 (2014) 8858-8873, http://dx.doi.org/10.1039/C4AY01373E.

[8] T. Madrakian, E. Haghshenas, M. Ahmadi, A. Afkhami, Construction a magneto carbon paste electrode using synthesized molecularly imprinted magnetic nanospheres for selective and sensitive determination of mefenamic acid in some real samples, Biosens. Bioelectron. 68 (2015) 712-718, http://dx.doi.org/10.1016/j. bios.2015.02.001.

[9] R.J. Uzuriaga-Sánchez, S. Khan, A. Wong, G. Picasso, M.I. Pividori, M.D.P.T. Sotomayor, Magnetically separable polymer (Mag-MIP) for selective analysis of biotin in food samples, Food Chem. 190 (2016) 460-467, http://dx.doi. org/10.1016/j.foodchem.2015.05.129.

[10] Y. Li, J. Liu, M. Liu, F. Yu, L. Zhang, H. Tang, B.-C. Ye, L. Lai, Fabrication of ultrasensitive and selective dopamine electrochemical sensor based on molecularly imprinted polymer modified graphene@carbon nanotube foam, Electrochem. Commun. 64 (2016) 42-45, http://dx.doi.org/10.1016/j.elecom.2016.01.009.

[11] A. Florea, C. Cristea, F. Vocanson, R. Săndulescu, N. Jaffrezic-Renault, Electrochemical sensor for the detection of estradiol based on electropolymerized molecularly imprinted polythioaniline film with signal amplification using gold nanoparticles, Electrochem. Commun. 59 (2015) 36-39, http://dx.doi.org/10. 1016/j.elecom.2015.06.021.

[12] P.S. Sharma, Z. Iskierko, A. Pietrzyk-Le, F. D'Souza, W. Kutner, Bioinspired intelligent molecularly imprinted polymers for chemosensing: a mini review, Electrochem. Commun. 50 (2015) 81-87, http://dx.doi.org/10.1016/j.elecom. 2014.11.019.

[13] R. Wang, Y. Wang, C. Xue, T. Wen, J. Wu, J. Hong, X. Zhou, Selective separation and enrichment of glibenclamide in health foods using surface molecularly imprinted polymers prepared via dendritic grafting of magnetic nanoparticles, J. Sep. Sci. 36 (2013) 1015-1021, http://dx.doi.org/10.1002/jssc.201201115.

[14] X. Xu, E. Duhoranimana, X. Zhang, Preparation and characterization of magnetic molecularly imprinted polymers for the extraction of hexamethylenetetramine in milk samples, Talanta 163 (2017) 31-38, http://dx.doi.org/10.1016/j.talanta. 2016.10.080.

[15] D. Gao, D.-D. Wang, Q.-F. Fu, L.-J. Wang, K.-L. Zhang, F.-Q. Yang, Z.-N. Xia, Preparation and evaluation of magnetic molecularly imprinted polymers for the specific enrichment of phloridzin, Talanta 178 (2018) 299-307, http://dx.doi.org/ 10.1016/j.talanta.2017.09.058.

[16] S. Khan, S. Hussain, A. Wong, M.V. Foguel, L. Moreira Gonçalves, M.I. Pividori Gurgo, M. del P. Taboada Sotomayor, Synthesis and characterization of magneticmolecularly imprinted polymers for the HPLC-UV analysis of ametryn, React. Funct. Polym. (2017), http://dx.doi.org/10.1016/j.reactfunctpolym.2017.11.002.

[17] A.N. Baeza-Fonte, I. Garcés-Lobo, M.D. Luaces-Alberto, L.M. Gonçalves, M.D.P.T. Sotomayor, A.C. Valdés-González, Determination of cephalosporins by UHPLC-DAD using molecularly imprinted polymers, J. Chromatogr. Sci. (2017) 1-7, http://dx doi.org/10.1093/chromsci/bmx099.

[18] M. Yang, H.L. Li, Determination of trace hydrazine by differential pulse voltammetry using magnetic microspheres, Talanta 55 (2001) 479-484, http://dx.doi.org/ 10.1016/S0039-9140(01)00456-8.

[19] F. Conzuelo, M. Gamella, S. Campuzano, A.J. Reviejo, J.M. Pingarrón, Disposable amperometric magneto-immunosensor for direct detection of tetracyclines antibiotics residues in milk, Anal. Chim. Acta 737 (2012) 29-36, http://dx.doi.org/10. 1016/j.aca.2012.05.051.

[20] S.V. Kergaravat, L. Beltramino, N. Garnero, L. Trotta, M. Wagener, M.I. Pividori, S.R. Hernandez, Electrochemical magneto immunosensor for the detection of antiTG2 antibody in celiac disease, Biosens. Bioelectron. 48 (2013) 203-209, http://dx. doi.org/10.1016/j.bios.2013.04.012.

[21] S.M. Marques, A. Santos, L.M. Gonçalves, J.C. Sousa, P.R. Bueno, Sensitive labelfree electron chemical capacitive signal transduction for D-dimer electroanalysis, Electrochim. Acta 182 (2015), http://dx.doi.org/10.1016/j.electacta.2015.09.169.

[22] R.M. Ramos, L.M. Gonçalves, V. Vyskočil, J.A. Rodrigues, Free sulphite determination in wine using screen-printed carbon electrodes with prior gas-diffusion microextraction, Electrochem. Commun. 63 (2016) 52-55, http://dx.doi.org/10. 1016/j.elecom.2015.12.010.

[23] R.M. Ramos, P.F. Brandão, L.M. Gonçalves, V. Vyskočil, J.A. Rodrigues, Electrochemical sensing of total sulphites in beer using non-modified screen-printed carbon electrodes, J. Inst. Brew. 123 (2017) 45-48, http://dx.doi.org/10.1002/jib.
402

[24] V.V. Jiri Barek, Karolina Peckova, Adsorptive stripping voltammetry of environmental carcinogens, Curr. Anal. Chem. 4 (2008) 242, http://dx.doi.org/10.2174/ 157341108784911325.

[25] E. Zacco, M.I. Pividori, S. Alegret, R. Galve, M.-P. Marco, Electrochemical magnetoimmunosensing strategy for the detection of pesticides residues, Anal. Chem. 78 (2006) 1780-1788, http://dx.doi.org/10.1021/ac0512610.

[26] L.M. Gonçalves, I.M. Valente, J.A. Rodrigues, Recent advances in membrane-aided extraction and separation for analytical purposes, Sep. Purif. Rev. 46 (2017) 179-194, http://dx.doi.org/10.1080/15422119.2016.1235050.

[27] R.M. Ramos, L.M. Gonçalves, V. Vyskočil, J.A. Rodrigues, Voltammetric determination of trace amounts of diacetyl at a mercury meniscus modified silver solid amalgam electrode following gas-diffusion microextraction, Talanta 169 (2017) 203-208, http://dx.doi.org/10.1016/j.talanta.2017.03.077.

[28] L.M. Gonçalves, M.F. da Anunciação, I.M. Valente, J.G. Pacheco, J.A. Rodrigues, A.A. Barros, Use of a membraneless extraction module for the voltammetric determination of total sulfites in wine, collect. Czechoslov, Chem. Commun. 75 (2010) 721-730 〈http://cccc.uochb.cas.cz/75/7/0721/〉.

[29] M.K. Sasaki, F.R.P. Rocha, A.D. Batista, D.L. Rocha, Flow-based food analysis: an overview of recent contributions, Anal. Methods 9 (2017) 6313-6334, http://dx. doi.org/10.1039/C7AY02350B.

[30] M. Saarnilehto, H. Chapman, T. Savinko, K. Lindstedt, A.I. Lauerma, A. Koivisto, Contact sensitizer 2,4-Dinitrochlorobenzene is a highly potent human TRPA1 agonist, Allergy Eur. J. Allergy Clin. Immunol. 69 (2014) 1424-1427, http://dx.doi. org/10.1111/all.12488.

[31] S.S. Vaidya, P.M. Gerk, Simultaneous determination of 1-chloro-2,4-dinitrobenzene, 2,4-dinitrophenyl-S-glutathione and its metabolites for human placental disposition studies by high-performance liquid chromatography, J. Chromatogr. B 859 (2007) 94-102, http://dx.doi.org/10.1016/j.jchromb.2007.09.006.

[32] R.J. Uzuriaga-Sánchez, A. Wong, S. Khan, M.I. Pividori, G. Picasso, M.D.P.T. Sotomayor, Synthesis of a new magnetic-MIP for the selective detection of 1-chloro-2,4-dinitrobenzene, a highly allergenic compound, Mater. Sci. Eng. C 74 (2017) 365-373, http://dx.doi.org/10.1016/j.msec. 2016.12.019.

[33] A.A. Konarev, V.T. Novikov, Polarographic behavior of 2,4-dinitrochlorobenzene and products of its reduction, Russ. J. Electrochem. 49 (2013) 81-85, http://dx.doi. org/10.1134/S1023193513010072.

[34] M.A. Prasad, M.V. Sangaranarayanan, Electrochemical reductive cleavage of carbon-chlorine bond in 1-chloro-2,4-dinitrobenzene, Electrochim. Acta 51 (2005) 242-246, http://dx.doi.org/10.1016/j.electacta.2005.04.019.

[35] I. Gallardo, G. Guirado, J. Marquet, Mechanistic studies on the reactivity of halodinitrobenzene radical-anion, J. Electroanal. Chem. 488 (2000) 64-72, http://dx. doi.org/10.1016/S0022-0728(00)00189-3.

[36] Z. Ullah, S. Hussain, S. Gul, S. Khan, F.K. Bangash, Use of HCl-modified bentonite clay for the adsorption of Acid Blue 129 from aqueous solutions, Desalin. Water Treat. (2015) 1-10, http://dx.doi.org/10.1080/19443994.2015.1027282.

[37] T. Zhou, Y. Feng, L. Zhou, Y. Tao, D. Luo, T. Jing, X. Shen, Y. Zhou, S. Mei, Selective and sensitive detection of tetrabromobisphenol-A in water samples by molecularly imprinted electrochemical sensor, Sens. Actuators B Chem. 236 (2016) 153-162, http://dx.doi.org/10.1016/j.snb.2016.05.153.

[38] Y. Hu, Z. Zhang, H. Zhang, L. Luo, S. Yao, Selective and sensitive molecularly imprinted sol-gel film-based electrochemical sensor combining mercaptoacetic acidmodified PbS nanoparticles with $\mathrm{Fe}_{3} \mathrm{O}_{4} @ \mathrm{Au}$-multi-walled carbon nanotubes-chitosan, J. Solid State Electrochem. 16 (2012) 857-867, http://dx.doi.org/10.1007/ s10008-011-1434-4.

[39] M.C. Blanco-López, M.J. Lobo-Castañón, A.J. Miranda-Ordieres, P. Tuñón-Blanco, Electrochemical sensors based on molecularly imprinted polymers, TrAC Trends Anal. Chem. 23 (2004) 36-48, http://dx.doi.org/10.1016/S0165-9936(04) 00102-5.

[40] H. Jiang, D. Jiang, J. Shao, X. Sun, Magnetic molecularly imprinted polymer nanoparticles based electrochemical sensor for the measurement of Gram-negative bacterial quorum signaling molecules (N-acyl-homoserine-lactones), Biosens. Bioelectron. 75 (2016) 411-419, http://dx.doi.org/10.1016/j.bios.2015.07.045.

[41] T. Alizadeh, Preparation of magnetic TNT-imprinted polymer nanoparticles and their accumulation onto magnetic carbon paste electrode for \{TNT\} determination, Biosens. Bioelectron. 61 (2014) 532-540, http://dx.doi.org/10.1016/j.bios.2014. 05.041.

[42] S. Patra, E. Roy, R. Madhuri, P.K. Sharma, Nanocomposite of bimetallic nanodendrite and reduced graphene oxide as a novel platform for molecular imprinting technology, Anal. Chim. Acta 918 (2016) 77-88, http://dx.doi.org/10.1016/j.aca. 2016.02.046.

[43] Q. Tang, X. Shi, X. Hou, J. Zhou, Z. Xu, Development of molecularly imprinted electrochemical sensors based on Fe 304 @MWNT-COOH/CS nanocomposite layers for detecting traces of acephate and trichlorfon, Analyst 139 (2014) 6406-6413, http://dx.doi.org/10.1039/C4AN01514B.

[44] A. Zamora-Gálvez, A. Ait-Lahcen, L.A. Mercante, E. Morales-Narváez, A. Amine, A. Merkoçi, Molecularly imprinted polymer-decorated magnetite nanoparticles for selective sulfonamide detection, Anal. Chem. 88 (2016) 3578-3584, http://dx.doi. org/10.1021/acs.analchem.5b04092. 